\title{
Depoimentos
}

\section{Influências cruzadas na constituição e na expansão do sistema de pós-graduação stricto sensu em educação no Brasil}

\author{
Menga Lüdke \\ Pontifícia Universidade Católica do Rio de Janeiro, Departamento de Educação, \\ Programa de Pós-Graduação em Educação
}

Este trabalho originou-se em uma entrevista concedida a Lucídio Bianchetti, em meados de 2004, sobre o processo de orientação de mestrandos e doutorandos, tema de sua pesquisa na época. Como atuo em cursos de pós-graduação desde o início dos anos de 1970, logo após concluir meu doutorado na França, suponho que entrei em sua amostra em função dessa longa experiência de orientação. Durante a entrevista foi se desenrolando, como era de se esperar, o relato sobre minha experiência como orientadora, mas também sobre minha própria vivência de formação acadêmica, tanto no Brasil como no exterior. Minhas percepções e impressões dessa vivência foram surgindo nas várias comparações que fiz entre as situações vividas em nossos programas, em termos de orientação de teses e dissertações, e as que vivi fora daqui, sobretudo na França e nos Estados Unidos, onde minha permanência foi mais prolongada. $\mathrm{Na}$ França, por pouco mais de três anos, para o doutorado, e nos Estados Unidos, numa primeira estada por um ano, na Florida State University, e numa segunda estada, por dois anos, para o pós-doutoramento, na Universidade da Califórnia, em Berkeley. Por certo foram essas comparações entre sistemas tão diferentes que levaram Lucídio a me convidar, em nome da revista da Associação Nacional de Pós-Graduação e Pesquisa em Educação (ANPEd), para ensaiar um esforço de situar os principais reflexos dos programas de pós-graduação em educação, já estabelecidos naqueles países, sobre os nossos próprios programas, incipientes ao final da década de 1960 e início da de 1970.

Devo dizer que fui levada a fazer um trabalho semelhante, há pouco tempo, a convite de uma revista francesa interessada em ver na minha trajetória acadêmica reflexos de diferentes culturas de pesquisa (Lüdke, 2003). Assim, senti-me estimulada, além de honrada, pelo convite da Revista Brasileira de Educação da nossa associação, em seu número comemorativo dos 40 anos da pós-graduação brasileira. Como a Pontifícia Universidade Católica do Rio de Janeiro (PUC-Rio), na qual trabalho há 30 anos, foi a primeira a instalar um curso de mestrado em educação no país, senti-me encorajada a aceitar o desafio, pois essa longa participação em um programa pioneiro me ofereceu a oportunidade de acompanhar e 
viver suas transformações, ao lado de um grupo de colegas muito bem qualificados, empenhados como eu em fazer o melhor trabalho possível. Tive também oportunidade de vivenciar a realidade de um outro programa, dentro de uma universidade pública, a Universidade Federal Fluminense (UFF), considerado um dos programas mais qualificados do país, o que permitiu enriquecer muito minha experiência e esclarecer minha percepção sobre várias questões que pretendo discutir neste texto.

Quero esclarecer, entretanto, que não se trata aqui do produto de uma pesquisa, ou mesmo de um estudo mais alentado sobre a situação de programas de pós-graduação, já bem estabelecidos em outros países na época em que os nossos se implantavam. Trata-se apenas da exposição franca de como eu vejo e sinto, hoje, as influências sofridas por nossos incipientes programas, naquela ocasião, e como foram eles reagindo a essas influências, dentro do quadro de fatores específicos do nosso contexto, desenvolvendo e integrando um sistema próprio, contando agora com mais de 70 programas.

Recorri a colegas que também tiveram oportunidade de freqüentar cursos de pós-graduação em outros países, mais ou menos nas mesmas épocas em que eu tive minhas experiências lá fora. Limitei-me aos programas da França e dos Estados Unidos, não apenas porque foram os que conheci mais de perto, pela minha própria vivência, mas porque considero que foram os que maior influência exerceram sobre o nosso sistema, de modo especial em seu período inicial. Por certo, idéias originárias de programas de outros países devem ter também exercido sua influência, mas eu não teria condições de procurar reunir informações sobre eles dentro do limite de tempo acordado para a elaboração deste trabalho, nem teria o contraponto da minha experiência pessoal para assegurar a perspectiva básica na qual ele seria feito: a visão de alguém que viveu essas diferentes realidades e procura detectar seus reflexos, em nossas instituições, por meio de uma longa trajetória de trabalho, de reflexões e de análise de nossa própria evolução no campo da pós-graduação em educação.
Os colegas que generosamente compartilharam suas experiências e impressões comigo - dois deles formados em universidades norte-americanas e uma outra em uma instituição francesa, como eu mesma não são responsáveis pelas análises e sugestões por vezes ousadas que me atrevo a fazer neste texto. Prefiro, por essa razão, não revelar seus nomes, mas registro meu agradecimento pela indispensável ajuda que me prestaram, ao pontuar e esclarecer, com seus depoimentos, aspectos específicos da realidade que vivenciaram lá fora, sempre à luz da grande experiência de trabalho em nossos programas e fino espírito crítico que os três possuem.

Quero ressaltar, também, que minhas observações incidirão muito mais sobre aspectos formais ou estruturais de nossos programas e como eles receberam forte influência de exemplos extraídos de outros sistemas, nos quais se inspiraram. Não seria possível tentar abarcar a variedade de correntes e contribuições teóricas que chegaram até eles, no seu início, e os acompanham desde então, constituindo mesmo um dos traços característicos, que comentarei mais adiante.

Quero iniciar minhas observações com um comentário sobre um documento fundador de nossa pósgraduação, a cuja leitura retornei agora, justamente a partir do desafio representado pela elaboração deste texto. Trata-se do parecer $n^{\circ}$ 977/65, da Câmara de Ensino Superior do Conselho Federal de Educação (CFE), relatado pelo conselheiro professor Newton Sucupira e aprovado em 3 de dezembro de 1965. A preocupação do então ministro da Educação, ao encomendar o estudo ao CFE, era que ele definisse e regulamentasse os novos cursos recém-criados pela Lei de Diretrizes e Bases da Educação Nacional (LDB lei no 4.024/61), cuja implantação tão necessária estava cercada de imprecisões. É bom lembrar que entre os conselheiros que aprovaram o parecer se encontravam nomes de enorme importância para a educação brasileira, como Durmeval Trigueiro Mendes, Alceu Amoroso Lima, Anísio Teixeira e Valnir Chagas. A leitura desse parecer é muito instrutiva para se entender os pontos de partida de nossos programas 
de pós-graduação, e é muito oportuna sua publicação neste número da revista da ANPEd, assim como o artigo de Carlos Roberto Jamil Cury, que o analisa de forma detalhada, para que nossos jovens alunos e colegas tenham acesso mais fácil a ele e possam, assim, refletir sobre aspectos que perduram até hoje em nossos cursos e o que significam.

A opção pelo modelo norte-americano é evidente no parecer do relator, que não deixa de reconhecer nele a influência da cultura germânica, como fica claro no trecho que transcrevo:

Mas o desenvolvimento sistemático da pós-graduação nos Estados Unidos pode ser considerado como produto da influência germânica e coincide com as grandes transformações da universidade americana nas últimas três décadas do século passado [séc. XIX]. É quando a universidade deixa de ser uma instituição apenas ensinante e formadora de profissionais, para dedicar-se às atividades de pesquisa científica e tecnológica. (Brasil, 1965, p. 69)

A preocupação com o desenvolvimento da pesquisa, por meio dos cursos de pós-graduação, para atender às necessidades de desenvolvimento do próprio país, vai ficando cada vez mais patente ao longo do parecer. Os cursos de graduação não seriam suficientes para preparar o pesquisador, embora devessem também se preocupar com sua iniciação. "Não se trata portanto, de transferir pura e simplesmente para o âmbito da pós-graduação todo esforço de treinamento científico” (idem, p. 71), mas de estimular e aperfeiçoar talentos que merecem um atendimento mais amplo nesses cursos. Para tanto, o modelo norte-americano é apresentado como exemplar, pois "sendo ainda incipiente a nossa experiência em matéria de pós-graduação, teremos de recorrer inevitavelmente a modelos estrangeiros, para criar nosso próprio sistema. O importante é que o modelo não seja objeto de pura cópia, mas sirva apenas como orientação" (idem, p. 74).

Vemos por essas afirmações como o relator estava preocupado em definir funções específicas para os novos cursos, sem destituir ou descaracterizar de suas funções próprias os cursos de graduação, já estabelecidos entre nós e destinados por excelência à preparação de profissionais. É interessante notar que, entre as especificidades dos cursos do novo nível (pósgraduação), ele ressaltava a preparação do professorado para atender à expansão do ensino superior (idem, p. 72). Essa função passou, de fato, a integrar as atribuições de nossos programas de pós-graduação, em todas as áreas, entretanto, sem a necessária discussão sobre como tal preparação precisaria integrar outros aspectos, além do estrito aprofundamento em determinada área de conhecimento.

O exemplo tomado emprestado ao sistema norte-americano, inspirador do nosso, partia de uma rigorosa seleção de seus candidatos, que, uma vez admitidos, deveriam seguir um certo número de cursos, participar de seminários e trabalhos de pesquisa e submeter-se a uma série de exames. Os cursos de mestrado e doutorado compreendiam uma área de concentração (major) à escolha do estudante e matérias de uma área conexa (minor). Para o doutorado, a tese era obrigatória, enquanto para o mestrado poderia ser exigida uma dissertação ou outro tipo de trabalho escrito, ou mesmo apenas os exames prestados. Estes eram numerosos e exigentes. O relator cita como exemplo um Master of Arts (MA) especializado em filosofia, que exigia três exames: a) um preliminar eliminatório sobre domínios básicos da filosofia, estipulados pelo departamento; b) um grande exame sobre o domínio de opção do estudante; c) um exame sobre campo conexo estranho à filosofia. Para o Ph.D., o candidato, além do domínio de duas línguas estrangeiras, deveria submeter-se: a) a um exame preliminar eliminatório sobre domínios determinados da filosofia, como para o mestrado; b) a um grande exame (comprehensive examination), em três partes (prova escrita sobre a especialidade escolhida, prova oral sobre história da filosofia e prova escrita sobre o domínio conexo); c) a um exame oral final sobre o assunto escolhido para a tese e o campo em que se situa (idem, p. 78). O relator ressalta o mérito desse sistema em não se limitar apenas ao preparo de uma tese doutoral ou dissertação de mestrado, mas ofere- 
cer ao aluno uma série de cursos, cobrindo amplamente o campo do conhecimento escolhido, visando a uma sólida formação científica e encaminhando-o ao trabalho de pesquisa. Tudo isso debaixo de uma assistência máxima e orientação ao aluno, respeitando sempre sua liberdade e iniciativa pessoal.

O mestrado e o doutorado constituíam níveis diferentes e autônomos de formação no sistema norte-americano, e, embora hierarquizados, não representavam exigência de seqüência obrigatória, havendo mesmo um tipo de mestrado de caráter mais profissionalizante, e também um doutorado específico para a área de educação, o Educational Doctor (Ed.D. - cujo prestígio nunca chegou a ser equivalente ao do Ph.D.). O relator dá conta desses detalhes e de muitos outros, que justificam uma leitura atenta do parecer, neste momento em que voltamos nosso olhar para os 40 anos de nossa trajetória de pós-graduação, tão marcada por esses traços iniciais, ainda que buscando sua própria identidade.

Em 1969, outro parecer também relatado por Newton Sucupira, parecer no 77/69 do CFE, estipula as condições de credenciamento dos cursos de pósgraduação, fixando as exigências explicitadas e defendidas no parecer $n^{0}$ 977/65. O processo de credenciamento, e recredenciamento a cada cinco anos, deveria assegurar o cumprimento dessas exigências, por todos os programas, "para que seus diplomas gozem de validade em todo o território nacional”. Para atender a essa exigência, mantida até os dias atuais, lembro muito bem que os coordenadores se concentravam na tarefa ingente de reunir e organizar todas as informações importantes do programa, para apresentação à comissão avaliadora, que viria visitá-lo e faria um relatório detalhado, mediante o qual seu credenciamento seria ou não renovado. Por certo esse mecanismo era um forte auxiliar na manutenção do modelo original, proposto para os nossos programas de mestrado e doutorado.

Na França, onde eu fazia então meu doutorado, o sistema era bastante diferente do norte-americano. Não havia propriamente um curso de mestrado, nem este era considerado exigência para o ingresso no doutorado. O candidato era admitido diretamente pela aceitação de um orientador de tese, que o considerava apto e compatível com seus interesses de pesquisa na época. Depois as coisas foram evoluindo, também em direção ao modelo norte-americano, com a exigência de um Diploma de Estudos Aprofundados (DEA - Diplôme d' Études Approfondues), mais ou menos equivalente ao nosso mestrado, para admissão ao doutorado. Mas isso em época bem mais recente, pois quando eu fazia meu “curso” praticamente não havia prescrição de disciplinas a serem cursadas ou de créditos a serem cumpridos, como era o caso do modelo norte-americano, que acabou inspirando os nossos cursos. Havia, por certo, uma oferta de disciplinas, asseguradas por grandes professores, nos anfiteatros dos belos e antigos prédios, como os da Sorbonne, onde tive oportunidade de assistir aulas de R. Aron e de P. Lazarsfeld, ou seminários da École Pratique de Hautes Études, como os de Touraine e Débovais, que tive o privilégio de acompanhar. Mas todos eles, e outros mais, foram sugeridos por minha orientadora, Viviane Isambert-Jamati, que me estimulava a segui-los, sabendo de sua importância para a minha formação. Não eram, entretanto, obrigatórios, nem contabilizados para o meu doutorado. Foi o caso, também, da colega que entrevistei para a elaboração deste texto, que se beneficiou de um trabalho muito bem cuidado, por parte de seu orientador, que integrava seu grupo de orientandos em atividades comuns, de estudos e de seminários ao redor de seu interesse de pesquisa. Mas esses casos constituem exceções, pois tanto ela como eu nos lembramos muito bem dos relatos de nossos colegas, que lastimavam conduzir seus trabalhos de doutorado praticamente sozinhos, encontrando seus orientadores muito raramente, alguns somente duas vezes ao ano. Havia, assim, uma grande flexibilidade dominando o sistema francês, muito mais centrado na tese de doutorado, que deveria representar um trabalho de fôlego, com boa fundamentação teórica e elaboração por parte do doutorando.

Como tive oportunidade de seguir para um estágio de um ano em uma universidade norte-americana, 
pouco tempo depois de minha volta ao Brasil, após meu doutorado, pude sentir bem claramente as diferenças entre os dois sistemas de pós-graduação, o francês e o norte-americano. Enquanto na França, de modo geral, os trabalhos se desenvolviam de forma bastante isolada, individualmente mesmo, orientador e orientandos agindo por conta própria, cada qual buscando seus interesses, com seus próprios recursos, muitas vezes bem limitados, nos Estados Unidos a cena era bem diferente. A vida de estudantes e professores literalmente se passava no campus, com uma intensa interação entre eles e, sobretudo, com condições materiais e de serviço para dar suporte a essa interação. Os estudantes moravam no campus, e os professores, diferentemente de seus colegas franceses, tinham seus offices também dentro do campus, onde passavam praticamente o dia todo, com tempos divididos entre aulas, seminários, trabalhos de pesquisa e horas específicas para atendimento aos estudantes.

As bibliotecas, muito bem equipadas, contendo todos os periódicos e obras importantes em cada domínio (ou podendo obtê-los facilmente de outras bibliotecas), com máquinas de xerox à disposição dos usuários, funcionavam 24 horas por dia, inclusive nos fins de semana... Havia facilidades para uso de computadores - já no início dos anos de 1970 -, e tudo era colocado à disposição dos estudantes de doutorado, a partir do trabalho atencioso dos orientadores e de seus assistentes. Tudo girava em torno do bom andamento de seus trabalhos de tese, com especial cuidado sobre o aspecto metodológico. Eram oferecidos muitos cursos obrigatórios, tratando de métodos e técnicas de trabalho em pesquisa, e todos os alunos de doutorado eram engajados em projetos ligados aos dos seus orientadores, o que lhes garantia a possibilidade de treinamento diretamente na prática da investigação.

O cuidado com o tratamento teórico do problema estudado era, entretanto, bem menos acentuado, como confirma minha entrevistada, que fez seu doutorado e pós-doutorado em universidade norte-americana. Exigia-se e cobrava-se, nos vários exames pelos quais o estudante de doutorado deveria passar, uma atenção especial aos passos da pesquisa, à escolha da amostra e dos instrumentos, à coleta de dados e sua análise (em geral usando recursos estatísticos), mas a atenção dedicada ao tratamento das questões teóricas ligadas ao problema em estudo era relativamente menor. Um mapeamento dos trabalhos mais importantes ligados ao problema, para situá-lo no cenário da literatura pertinente, com a indispensável articulação e elaboração pelo estudante das idéias centrais de seus autores, era considerado suficiente para a aprovação da tese. Quero ressaltar que se trata aqui de registrar minhas impressões bastante gerais sobre o que consegui ver durante os períodos em que estagiei em universidades norte-americanas, convivendo com muitos colegas de várias nacionalidades, além dos brasileiros, o que corresponde também à impressão da colega entrevistada. Por certo, há exemplos de teses feitas naquelas universidades que constituem trabalhos com tratamento teórico muito bem cuidado. Parece-me, entretanto, que se trata de uma proporção menor de trabalhos, a maioria aproximando-se de um modelo com forte predomínio do cuidado metodológico, em comparação com o aspecto teórico.

No Brasil, as influências desses dois modelos sumariamente esboçados, o francês e o norte-americano, foram sendo assimiladas ao lado de outras influências. E, com base em nossas necessidades e em nossos recursos, foi-se constituindo um sistema novo, próprio, com características originais, embora mostrando marcas daquelas influências.

As primeiras dissertações, defendidas ainda na década de 1970, nos poucos programas já implementados no país, ilustram um aspecto bastante original de nosso sistema. A despeito de estarem procurando cumprir os preceitos do parecer $n^{\circ} 977 / 65$, com a divisão entre áreas de concentração, disciplinas obrigatórias e optativas, numerosos créditos a cumprir e exames de qualificação a passar, nossos programas acolhiam e estimulavam, também, o desenvolvimento de dissertações bem pouco aproximadas de um trabalho empírico vultuoso, bem mais voltadas para o estudo aprofundado de uma questão de cunho teórico, mais próximas, portanto, do modelo francês que do norte-americano. Pa- 
rece-me que esse traço de valorização do aspecto teórico do trabalho de dissertação ou tese vem acompanhando a evolução de nossos programas, ainda que por vezes não passe de uma preocupação, não chegando sempre ao cumprimento satisfatório dessa expectativa. Vários fatores ajudam a entender esse não cumprimento, entre eles a própria identidade da educação como campo de confluência de várias disciplinas, exigindo uma formação plural do futuro pesquisador, em diferentes domínios teóricos, o que nem sempre é viável dentro das condições em que se deu a expansão da rede de programas de pós-graduação por todo o país. Estou juntando assim fatores de natureza epistemológica e de cunho sociopolítico, como é inevitável, para tentar entender como, ao longo da nossa história, fomos construindo, como nos foi possível, com nossos ingredientes fundadores, a nossa formação em nível de pós-graduação.

Tínhamos, naquela época inicial, tanto dos programas de mestrado, como depois dos de doutorado, uma demanda reprimida muito bem qualificada, como costumávamos comentar então. Ela era composta por professores que vinham há muito acumulando sua experiência no magistério do ensino superior e amadurecendo suas reflexões e análises sobre problemas da educação. Assim, vinham eles fazer o mestrado, ou o doutorado, com esse acúmulo, ou esse "capital”, como diria Bourdieu, investido então num esforço de qualificação formal, através do curso, que desembocaria no título de mestre ou de doutor. Esse capital entrava em composição com a organização flexível que adotamos para os nossos cursos, apesar de partirem, em princípio, do esquema bem mais estrito dominante nas instituições norte-americanas.

Fomos evoluindo como podíamos, dentro dos nossos limites de recursos e ante as exigências de atender às diversidades regionais de nosso país. Despertamos para a urgência de desenvolvimento das atividades de pesquisa e lançamos mão da idéia de linhas de pesquisa, de inspiração norte-americana. Não tínhamos, entretanto, as mesmas condições de desenvolver grupos de pesquisa, reunindo professores e estudantes, como se fazia de longa data nas univer- sidades norte-americanas. Mas há muito vínhamos nos preocupando com esse aspecto, e agora me parece evidente a mudança cultural já ocorrida, sustentada sobretudo pelo Conselho Nacional de Desenvolvimento Científico e Tecnológico (CNPq), no caminho da multiplicação desses grupos, hoje apresentando uma atividade intensa, em várias das nossas universidades, ainda que não em todas. São as bolsas de auxílio ao pesquisador e de iniciação científica para os estudantes de graduação que representam, sem dúvida, a melhor maneira de desenvolver futuros pesquisadores, pela participação em grupos de pesquisa.

Conservamos, desde os primeiros cursos de pósgraduação, um gosto pelo aprofundamento teórico, mais ao estilo francês, como já comentei, ainda que nem sempre cumprido pela nossa produção acadêmica, especialmente no que se refere às dissertações. Também conseguimos guardar uma certa abertura a diferentes correntes de pensamento, vindas de várias origens, o que muitas vezes surpreende colegas franceses ou norte-americanos, que nos visitam e observam a variedade de fontes bibliográficas das quais nos servimos, quando eles, em geral, se restringem à literatura de sua própria língua, quando não de seu próprio país. Essa abertura, aliada à flexibilidade com que implantamos o modelo sugerido pelo parecer $\mathrm{n}^{\circ}$ 977/65, facilitou, por exemplo, a entrada das abordagens qualitativas em nossas pesquisas, o que tardou bem mais a ocorrer na pesquisa educacional norteamericana. É verdade, também, que o caminho ficou assim aberto para um certo excesso no uso de recursos dessas abordagens, sem o devido cuidado com suas especificidades, com conseqüências sensíveis não apenas sobre o conjunto de dissertações e teses, mas de toda a pesquisa da área de educação.

Acho oportuno lembrar, neste pequeno e ousado ensaio de comparação pluricultural, como, nas adaptações dos modelos que nos inspiraram na implantação de nossos programas de pós-graduação, fomos extraindo de nossas fontes pessoais recursos para enfrentar as precárias condições de trabalho, em comparação com as disponíveis no cenário de outros países, especialmente no norte-americano. No que diz 
respeito à orientação, por exemplo, acho que conseguimos desenvolver um trabalho que ultrapassa, por vezes, limites extremos, graças, em muitos casos, à nossa disponibilidade e também à nossa facilidade de contato pessoal. Chamo a atenção para esse aspecto, pois, no caso francês, a comparação nos favorece, por essa facilidade de acolhida e de contato que nos caracteriza e faz com que nos aproximemos de nossos orientandos. E, no caso norte-americano, é a nossa disponibilidade para o trabalho em condições longe das ideais que nos estimula a buscar ajuda para nossos estudantes, seja em termos de bibliografia, seja mesmo em questões pessoais, atendendo-os em nossas próprias casas, em fins de semana, ou em longos telefonemas, quando estão em suas cidades de origem. Agora, com as facilidades da Internet, desenvolve-se um outro tipo de comunicação, mas prefiro nem tocar nesse tema, que demandaria uma análise cuidadosa para se extrair alguma conclusão a respeito.

Também gostaria de sugerir, neste pequeno balão de ensaio, como já poderíamos estar avaliando ganhos e perdas decorrentes de nossas relações com os modelos inspiradores, no início muito necessários, imprescindíveis mesmo, como assinala Sucupira no parecer $n^{\circ} 977 / 65$, aos poucos se tornando dispensáveis ou até indesejáveis, na medida em que fomos compondo nosso próprio modelo. Hoje já atingimos um ponto de maturidade capaz de assegurar uma produção teórica própria, comparável à que é desenvolvida em outros países com maior tradição na área educacional, e que poderia e deveria ocupar o espaço que lhe é devido. Temos uma grande diversidade regional, com implicações sérias e históricas sobre a expansão desigual de nosso sistema de pós-graduação. Poderíamos aproveitar melhor os recursos que já desenvolvemos, para o atendimento de programas em fase de implantação, pois estaríamos, assim, bem mais próximos das soluções mais compatíveis com os nossos problemas, do que as importadas de outros centros, que às vezes fazem seus portadores se sentirem como "estrangeiros dentro de sua própria terra”, como observou um dos meus entrevistados.
Este depoimento reúne apontamentos e reflexões que podem servir de pistas para futuros estudos a respeito da hibridez no processo de constituição e expansão da pós-graduação em educação no Brasil, assim como sobre o quanto conseguimos avançar na construção de uma proposta autóctone, na qual particular e universal se juntam, procurando aproveitar o melhor de soluções vividas por sistemas mais maduros que o nosso.

MENGA LÜDKE, doutorada em sociologia pela Universidade de Paris e com pós-doutorado na Universidade da Califórnia, em Berkeley, e no Instituto de Educação da Universidade de Londres, é professora no Departamento de Educação da Pontifícia Universidade Católica do Rio de Janeiro (PUC-Rio), atuando no Programa de Pós-Graduação em Educação. Publicou: La profession enseignante face à la politique actuelle de la formation des maîtres au Brésil (In: BIRON, D., CIVIDINI, M., DESBIENS, J. (orgs.). La profession enseignante au temps des reformes. Paris: Éditions du CRP, Université de Sherbrooke, 2005, p. 242-262); em co-autoria com BOING, L. A., Caminhos da profissão e da profissionalidade docentes (Educação e Sociedade, Campinas: CEDES, v. 25, nº 89, set.dez. 2004, p. 1.159-1.180); e coordenou O professor e a pesquisa (Campinas: Papirus, 2004, $3^{\text {a }}$ ed.). Pesquisa atual: O que conta como pesquisa? Estudo dos critérios de avaliação de trabalhos de pesquisa apresentados por professores a membros de comitês julgadores de eventos científicos, de publicações em periódicos e de órgãos de financiamento.E-mail: menga@edu.puc-rio.br

\section{Referências bibliográficas}

BRASIL, (1965). Parecer nº 977/65. Documenta, Rio de Janeiro, MEC/CFE, n ${ }^{\circ} 44$, p. 67-86.

BRASIL, (1969). Parecer $n^{\circ}$ 77/69. Normas do credenciamento dos cursos de pós-graduação. Documenta, Rio de Janeiro, $\mathrm{n}^{\circ}$ 98, fev., p. 128-132.

LÜDKE, Menga, (2003). Une sociologue brésilienne au croisement de diverses cultures de recherche. Perspectives Documentaires en Education, Paris, ${ }^{\circ}$ 59, p. 19-28.

Recebido em maio de 2005 Aprovado em junho de 2005 


\section{Resumos/Abstracts}

Menga Lüdke

Influências cruzadas na constituição e na expansão do sistema de pósgraduação stricto sensu em educação no Brasil

Trata-se de depoimento sobre as principais influências sofridas pelos programas de mestrado e doutorado no Brasil, em seu início, a partir de modelos já bastante desenvolvidos nos anos de 1960 e de 1970, em países como a França e os Estados Unidos. Como tive oportunidade de viver nesses países, como estudante de pós-graduação, voltando para o Brasil quando se implantavam os primeiros programas, pude conferir pessoalmente essas influências e seus resultados. Claro que se trata de uma visão pessoal, limitada à minha própria experiência, sem aprofundamento por meio de um estudo ou uma análise mais cuidada. Entretanto, pude confrontar minhas impressões com as de colegas, que viveram experiências semelhantes e confirmam as minhas, mas assumo inteira responsabilidade pelas interpretações que apresento no texto, como sugestões para outras interpretações e estudos, que venham a aprofundar pistas que tenha conseguido levantar.

Palavras-chave: pós-graduação; Brasil; França; Estados Unidos

Differing influences on the constitution and expansion of the system of postgraduate studies in education in Brazil

This text deals with the principal influences suffered, at their outset, by Master's and Doctoral Programmes in Brazil, based on models already well developed in the period 1960/70, by countries like France and the USA. As I had the opportunity to live in these countries as a postgraduate student, from where I returned to Brazil when the first programmes were being implanted, I was able to confer such influences and their results. This is clearly a personal view, limited by my own experience, and not furthered by means of a study or more careful analysis. However, I was able to confront and confirm my impressions with those of colleagues who lived similar experiences but nevertheless I accept total responsibility for the interpretations which I present in the text as suggestions for other interpretations and studies which may further the suppositions which I have managed to raise.

Key-words: postgraduate studies;

Brazil; France; United States of

America 